\title{
Schools and Kindergartens as Shared Workplaces - An analysis of the work ability management challenges of the meal and cleaning service employees
}

\author{
Päivi Kekkonen* and Arto Reiman \\ Industrial Engineering and Management, University of Oulu, Finland \\ P.O. Box 4610, FI-90014 University of Oulu, Oulu, Finland \\ *Email: paivi.kekkonen@oulu.fi, Phone: +358505997118
}

\begin{abstract}
BACKGROUND: Service organizations and their employees encounter challenges today due to an increase in the average age of employees, a decrease in recruitment, and changes in work tasks, sites, and communities. These factors give rise to physical and psychosocial burdens that can lower the work ability and productivity of the employees.
\end{abstract}

OBJECTIVE: The goal of this study is to find practical solutions for challenges related to the work environment and practices at a public in-house enterprise providing meal and cleaning services. Also, the design of a model for the management of these load factors at municipal workplaces, where stakeholders from different subdivisions work together, is intended.

METHODS: The materials comprised of documents provided by the case organization, interviews, and work observations. Root cause analysis and participatory development sessions were carried out to find causes for the observed challenges and to discover practical solutions. RESULTS: A number of microergonomic solutions were found. Also, broader subjects for development, common to several target workplaces, were discovered. 
CONCLUSIONS: The concept of a shared workplace, proved useful in exploring ways to manage work ability and productivity. A generalizable macroergonomics model for the management of load factors at shared workplaces in the public sector was proposed.

Keywords: Load Factors, Macroergonomics, Participatory Development, Public Sector, Work System. 


\subsection{Introduction}

The continuous and increasing changes of work life set new challenges for organizations. While the average age of employees is increasing, there is a simultaneous decrease in recruitment due to budgetary reasons. Job positions and work tasks are also constantly examined and re-structured for optimization purposes. These factors cause both physical and psychosocial burdens that can lower an employee's work ability and productivity [1]. Organizing the work in such a manner that it is both suitable for an employee and maintains the work ability of said employee throughout his or her work career is a challenge. Also, the common goal of the municipal processes in being able to provide a sense of well-being at different levels may become unclear in today's organizational environment [1]. Work should be planned so that it enables both the healthy and productive operation of an employee as well as promotes his or her experience of the significance of the work [2-4]. In terms of the principles of sustainable development, the planning of work should consider the needs of all stakeholders in the long term as well [5].

Over the last decades, the number of workplaces in which there are employees of several different employers has increased as organizations focus on their core businesses and subcontract many support services [6-8]. This development has resulted in networks and work environments that rely heavily on the co-operation of the companies that are involved [9]. In most cases, the outsourced operations are 'support operations' that are needed to run the core operations of the company [10]. Support operations cover services such as financial administration, security, and maintenance of the premises and machinery [11]. Outsourcing the support operations can be seen as 
an opportunity for a company to focus on its core operations and, thus, to gain business advantages by concentrating on its area of expertise [12-13]. On the other hand, the support operations for an organization can also be produced by internal service providers, such as specialized units or shared service centers in the form of municipal business units [8]. In these kinds of situations, the actors providing support operations might operate in a similar organizational culture to the employees carrying out the core operations. However, the coordination of their actions in order to guarantee successful cooperation is important.

When an organization outsources or subcontracts some of its operations to another organization, this often leads to the emergence of a shared workplace, especially in the manufacturing and construction industries [9]. By definition of the Finnish legislation, a shared workplace is a workplace where one employer exercises the main authority while other employees of several employers or self-employed individuals work simultaneously or successively so that their work can affect other workers' safety and health. In this case, the employers and self-employed individuals are required by mutual cooperation to make sure that their actions do not endanger the health and safety of any employee at the workplace [14]. The situations and operations at shared workplaces have been studied previously, especially in manufacturing, construction, and transportation and storage sectors [6, 15-17].

Networks based on the cooperation of organizations and shared workplaces form systems that can be considered as complex organizations or consortiums of organizations. The study of these kinds of organizations requires both microergonomic examination, concentrating on the individual actors, as well as macroergonomic, or intra- and interorganizational system-level, approaches [18-19]. Macroergonomics, 
arising from socio-technical system theory, includes a physical, a social, and an organizational context that are present in a system comprised of several intertwined sub-systems that interact with each other [20-21].

Work carried out by an employee can be studied using the framework of the work system. The work system encompasses the person (employee), his or her work task, the tools and technologies he or she uses to accomplish the task, the work environment, and the organization in which the work takes place [20, 22-23]. The work can be perceived as consisting of processes that result in either positive or negative outcomes, depending on the input and the interrelation among the sections in the work system [23]. The role of psychosocial factors, information and communication within the work system and the interrelation of its elements has also been acknowledged [24]. Examples of positive outcomes include the productivity, health, and wellbeing of the employees while negative outcomes include stress, accidents, discomfort, absence from work, and the loss of time. The ergonomic development of work, fitting the work for the human being, can be seen as an optimization that aims to enhance the well-being and productivity of the employee [25].

According to many studies, allowing employees to participate in the development of their own work increases both well-being and productivity at work [25]. The concept of participatory design and development covers all design and development activities where the users of the systems or products are systematically involved in and actively provide input into the design and development process. For example, common design tools include different kinds of models and prototypes, analysis methods, and check-up lists as well as various discussion, ideation, and group 
work techniques [26]. Thus, participatory design aims to extract and utilize the tacit knowledge possessed by the users or employees [27].

This study focuses on a municipal organization and the actors within it from the viewpoint of cooperation. As previously mentioned, outsourcing has increased the occurrence of both shared workplaces and situations that are in many ways similar to shared workplaces. In the municipal sector, it is common that certain tasks are transferred to separate subdivisions, business units, or shared service centers. With respect to the precise definition of a shared workplace according to Finnish legislation, this study considers a similar situation where there are several actors working at the same workplace, but they are all employed by the municipality; due to this, the definition of a shared workplace is not fulfilled completely. However, the in-house enterprise in this article is ran by its own managing director and has its own budget, and is thus in many ways referable to private enterprises. Also the work of the employees of the core operations and the in-house enterprise is organized in a manner that heavily resembles that of a shared workplace: Their tasks and tools are different (core operations vs. support operations) and they represent different professions and come from at least to some extent from different organizational cultures, but they share a common work environment, where their work can have an effect on the health and safety of the other party.

In this article, we focus on a participatory ergonomics development process [28] in which both macroergonomic and microergonomic development needs [21] were identified inside a municipal organization. An important focus of this project is to examine if the concept of a shared workplace could be useful for finding means to successfully manage work ability and productivity within municipal workplaces. 


\subsection{Objectives of the study}

The case organization in this study is a public in-house enterprise that provides meal and cleaning services. The case organization and its' work ability management processes, supplemented with economic analyses, have been discussed previously by Reiman et al. [1]. In their research, further studies on the workplace level were recommended as a topic for future research. In this study, we respond to this research challenge by providing an in-depth study of two kindergartens and four schools to which this public in-house enterprise provides its services. In our research, the subject workplaces were considered shared workplaces where different actors interacted to provide services aimed at educating children and youngsters. Our special interest was to identify microergonomic occupational safety and health (OSH) development needs and to provide a macroergonomic development process in which solutions for these challenges are provided.

A prerequisite for our study was to include all stakeholder groups working at the target workplaces in the development process. Even though the public in-house enterprise providing the meal and cleaning services was our initial observation unit, we expanded our study to cover all relevant actors at these workplaces. This included the employees, management, and OSH actors from all sectors. Identifying and engaging all relevant stakeholder groups to the OSH development process was the first research task.

By engaging these stakeholder groups in collaborative work, management practices were brought forward to further spread best practices, healthier work environments, and improved work communities. This was carried out by first identifying microergonomic development needs and after that finding solutions to them 
in participatory manner. This constituted the second research task. The principles of continuous improvement were also present throughout the participatory process.

Furthermore, macroergonomics were emphasized, as the cooperation processes and organizational practices inside the shared workplaces and inside the municipal organization were assessed. A wider goal of the study was to formulate a generalizable model for the management of harmful load factors at shared workplaces. This was the third research task.

This study yields an analysis of the physical and psychosocial load factors that occur at shared workplaces of a municipal organization from the viewpoint of meal and cleaning services employees. Also the actors needed to find and implement solutions in order to reduce the harmful effect of these load factors are contemplated. In addition, a management model that could be used to manage the work ability at such shared workplaces, is considered.

\subsection{Methods}

This section presents first the target workplaces of the study and the stakeholder analyses carried out for each target workplace. Second, the participatory development process, consisting of the analyses of past and present situations as well as the actual participatory development carried out at these workplaces, is explained.

\subsection{Target workplaces}

The materials for this study were gathered from six workplaces: two kindergartens and four schools. All target workplaces were public kindergartens and schools administered by the municipality - a city of approximately 200000 inhabitants. 
The target workplaces were chosen so that they would form a representative sample of workplaces where the meal and cleaning services employees of the municipal case organization work. This was realized by including target workplaces that consisted of both old and new buildings, where old ones were not necessarily suitable for today's requirements and one was also listed. One building was also under renovation at the moment of the study. Target workplaces consisted also of both small and large units in terms of numbers of students and kindergarten children. In addition, both individual units and units with many other operations, such as library, youth work etc., were considered.

The choices regarding the target worksites were made by a multi-professional working group consisting of representatives of case organization, human resources, occupational health services, and education and culture services including upper management, middle management, specialists and employee representatives. The target worksites were characterized by the following properties (hereafter, the target worksites are referred to by their respective acronyms):

- K1: Kindergarten operating in an old building.

- K2: Kindergarten operating in a new building.

- S1: School with a small number of students operating in a new building.

- S2: School with a large number of students operating in a new building together with many other operations, such as a library, a kindergarten, and youth work.

- S3: School with a large number of students operating in an old, listed building. 
- S4: School with a large number of students operating in an old building under renovation.

\subsection{Stakeholder analysis}

As mentioned, the target workplaces were considered shared workplaces although the researchers identified that these workplaces did not necessarily fulfill all the requirements for a shared workplace according to the Finnish legislation since all of the workplaces' employees eventually worked under one employer (the municipality). The actors of each of the target workplaces are presented in Table 1 with crosses. There were meal and cleaning services employees of the case organization working at each kindergarten and school. In addition to the actors listed in Table 1, who work permanently at the target workplaces, there were also actors who irregularly carried out work tasks on the school or kindergarten premises or who were important stakeholders in relation to the operations carried out at the school but primarily worked elsewhere. These actors included the supervisors and the OSH actors of the meal and cleaning services provider, education and culture services, and technical services of the municipality as well as real estate managers working for the technical services. Altogether, these actors formed the group of stakeholders that were engaged in the participatory development process depicted in the following discussion.

Table 1. Actors in the target workplaces (crosses) and the number of representatives of each stakeholder group taking part in the participatory development sessions (in parenthesis). Many of the meal and cleaning service employees are multi-service employees who work at both meal and cleaning services. This is reflected in the $1 / 2$ numbers used in the table.

INSERT TABLE 1 HERE 


\subsection{The participatory development process}

After choosing the target workplaces and identifying the relevant stakeholders in each case, the following development process, covering the past, present, and iterative participatory development aspects, was carried out in each target workplace. The development process took place over a nine-month period between spring and autumn 2017

\subsubsection{Past}

At the beginning, the past instantiations of the target workplaces were analyzed by utilizing multiple data sources. These included workplace specific OSH statistics provided by the management and human resources of case organization, accident and near-miss data provided by the municipal OSH organization, risk assessment reports and personnel surveys provided by the case organization, as well as workplace survey reports from their occupational health service provider.

3.3.2 Present

After the background analysis, the current instantiations of the target workplaces were assessed in terms of work environments and practices. This was carried out through observations of work and interviews. The observations were performed by following the cleaning and meal services personnel during their daily work routines for approximately 0.5 workdays per each of the six workplaces. The work observations were executed by one or two researchers at a time, in cooperation with the OSH representative of the case organization in most cases. The personnel of the target workplaces were also directly interviewed during the observations.

\subsubsection{Participatory development}


Based on the analysis of the past and present instantiations, the researchers made tentative proposals for the most significant development targets for every workplace. Visualized descriptions were formed, which contained both written and visual information about the observed individual challenges as well as their causes and the possible solutions that had been previously suggested during the observations. The development challenges were divided according to their origins into physical and psychosocial categories by the researchers.

Participatory development sessions, which were organized in the form of workshops, aimed to engage personnel from all groups at the target workplaces, as well as other actors relevant to the workplace operations, in identifying development solutions for the observed challenges. All relevant stakeholder groups of each workplace listed in Table 1 were invited to take part in the development of the work environment and the practices of the meal and cleaning services employees. Table 1 also lists the number of representatives of the employee groups, employers, and OSH personnel who took part in the workshops at each target workplace. At some workplaces, representatives of stakeholders functioning in the same building, such as library staff, youth workers, or caretakers, were also present. The total number of participants in the workshops varied from 5 to 9 persons in addition to 1 or 2 researchers acting as facilitators of the workshop.

Participatory development sessions resulted in both new practical ideas and sharing of best practices that were already at use. The sessions also elicited tacit knowledge possessed by different employee groups. The lean-oriented 5 Whys methodology was utilized in the sessions to identify the root causes for the challenges [29]. Essentially, the question "Why?" was expressed several times for each identified 
development challenge to identify the root of the problem; after which, the question was changed to "How?" to solve these problems.

\subsection{Results}

This section presents an analysis of the physical and psychosocial load factors that occur at the target workplaces of the case organization from the viewpoint of meal and cleaning services employees. The actors needed to find and implement solutions in order to reduce the harmful effect of these load factors are contemplated together with the management model for work ability in the discussion within Section 4 .

The past and present phases described above provided material for the root cause analyses and the following participatory development phase. Example visualizations of the root cause analyses are presented in Figures 1 and 2 for the musculoskeletal disorders caused by the physical load factors of the meal service employees and the psychosocial load factors experienced by meal and cleaning services employees working at a kindergarten. After the root cause analysis described in the previous section, it was easier to find the solutions to the problems; this was the aim of the participatory development sessions.

\section{INSERT FIGURE 1 HERE}

Figure 1. The results of the root cause analysis conducted on the musculoskeletal disorders caused by the physical load factors in the work of the cleaning service employees working at a kindergarten.

INSERT FIGURE 2 HERE 
Figure 2. The results of the root cause analysis conducted on the psychosocial load factors in the work of the meal and cleaning services employees working at a kindergarten.

\subsection{The development challenges}

The development challenges identified at the target workplaces were divided into 15 separate themes according to their origins. In the second round of the analysis, these themes were further categorized utilizing the elements of the work system, namely, the organization, task, tools and technology, and work environment. There were no development challenges categorized under the work system element of employee. This was due to the fact that in the case of the identified challenges, only few could be connected to the acts of the employees of the meal and cleaning services provider themselves and/or be solved by them. Also, the focus of the process was more in the identification of organizational, technological and work environment related factors instead of the actions of an individual employee and his or her responsibilities regarding the management of the load factors of his or her own work. This is further elaborated upon in the discussion within Section 4.

The number of practical challenges related to each theme in each kindergarten (K1-K2) and school (S1-S4), respectively, as well as the total number of solutions suggested in the participatory workshops are listed in Table 2 . The solutions suggested in the workshops included both new practices and good practices already in use at some workplaces that could be spread to other worksites through the different stakeholders taking part in the workshops. 
Table 2. The number of development challenges identified at each kindergarten (K1, K2) and school (S1-S4) acting as a target worksite. The final column presents the number of new solutions and identified good practices suggested in the workshops.

\section{INSERT TABLE 2 HERE}

\subsection{General subjects for development}

In addition to the development challenges listed in Table 2, broader subjects for development that were common to several worksites were recognized during the process. These included challenges in identifying and engaging all stakeholder groups in the initial foundational planning process of the premises, promoting communality between the actors of the shared workplace, the demand and supply of knowledge related to ergonomics among the employees, and recognizing the mutual interest of the community in addition to the interest of individual actors or organizations.

\subsubsection{Challenges in identifying and engaging all stakeholder groups}

It was discussed in the participatory development sessions that the different user groups of the premises with their various needs were not necessarily identified well enough. This could lead to not engaging all needed end-user groups in the initial foundational planning of the premises. At several target workplaces, for example, the facilities reserved for cleaning centers were not sufficient or did not fulfil the needs of the cleaning service work. Also at some workplaces the kitchen facilities no longer matched today's requirements. Taking part in the planning committees of the municipal real estate management department was seen as an important part of the solution. In the cases of many current building and renovation projects, the representatives of the meal and cleaning services provider were already involved in the initial planning. In addition, 
closer collaboration between the stakeholder groups of the shared workplace, and especially their respective OSH organizations, was desired. For example, regular meetings involving all stakeholder groups were seen as one solution for continuous improvement.

\subsubsection{Promoting communality between the actors of the shared workplace}

Promoting the sense of community between the actors of the shared workplace was seen as important as well. At several target workplaces, there were already many good practices in use that fostered communality. These included common break rooms and coffee breaks among the employees of the school or kindergarten and the meal and cleaning services employees. The work communities had also developed various methods for interaction and information exchange, such as notice boards and notebooks if there was not enough time for dialogue during work. There were also local practices regarding task allocation for work tasks demanding physical strength. For example, the employees of the school or kindergarten aided cleaning service employees by carrying heavy paper packages or moving furniture. Respectively, in many occasions the drivers delivering the meal supplies brought them into kitchen facilities and placed them on carts to ease the handling of heavy packages. At some target workplaces, the meal and cleaning services employees were seen as integral members of the work community, and they were self-evidently also invited to take part in the staff parties or special occasions, whereas, at other workplaces, this was not a general practice. Thus, the experienced sense of communality varied across the target workplaces. The headmaster of one of the target workplaces where the employees of different personnel groups experienced strong communality summarized this sense of communality as, "It is nothing more than just being open-minded both ways!" 
4.2.3 The demand and supply of knowledge related to ergonomics among the employees

There is a need for ergonomic knowledge regarding both the work tasks of the meal and cleaning services employees themselves as well as the choices made by other actors that have an effect on the work load experienced by the meal and cleaning services employees. In addition to a user-oriented design of the premises, knowledge related to usability and ergonomics as well as the identification of all the user groups are necessary in procurement. With the right knowledge, it is possible to decrease the physical load factors experienced by the employees. It was raised in the participatory development sessions that the representatives of the schools or kindergartens who made the procurement decisions regarding the furniture, e.g., carpets or garbage cans, did not have sufficient knowledge of the properties that affect the usability of these items in terms of cleaning services. Choosing the right type of machinery, such as dishwashers, for the kitchen facilities, demands also knowledge on ergonomics. As a means to enhance the ergonomics knowledge of meal and cleaning services employees themselves, the following actions were proposed: more pronounced utilization of the knowledge and guidance of the meal and cleaning services work managers, the induction to work, the maintenance of one's own workmanship, and various campaigns by the organization.

\subsubsection{Recognizing the mutual interest of the community}

In the participatory development sessions, it was found that, in some cases, the roles and the work of other actors at the shared workplaces were unfamiliar to the employees even though their actions at work would have an effect on the work of the other actors. Therefore, recognizing one's own role as well as the roles of the other actors as parts of a whole would benefit the collaboration and the general functioning. 
Furthermore, the interest of the whole municipality (including the kindergarten children and the students) should be acknowledged in addition to the sole interests of each individual actor or organization.

\subsection{The model for managing OSH problems at shared workplaces}

The participatory development process was aimed toward designing better operational models and work practices as well as creating safer and healthier work environments and communities by finding concrete and practical solutions to the observed challenges. The process of utilizing the participatory design and the cooperation of the various stakeholders also represented a model for the collaboration of the different stakeholders and collective engagement in the development of work at shared workplaces. This could also be seen as a model that could be used in continuous improvement at the case organization. A simplified, generalizable model for identifying and managing OSH problems at shared workplaces in the public sector was also created for future use as a result of the development process.

The model, which was based on the analysis of background materials related to the current OSH instantiation in the organization, observations carried out at the workplace, and participatory development workshops that engaged all relevant stakeholder groups, was developed and determined to be functional. In addition to solutions to individual development challenges, this process also elicited information on the management of larger subjects for development, which can be generalized to other similar municipal workplaces. The model, presented in Figure 3, consists of successive phases of making the decision to start the development process, the 
utilization of background material, the identification of the actors, the development process, the setting of goals for the change, and the follow-up of the change process.

\section{INSERT FIGURE 3 HERE}

Figure. 3. The model formed for the management of physical and psychosocial load factors at shared workplaces in the municipal sector.

\subsection{Discussion}

In this research, the concept of a shared workplace was applied to worksites in the municipal sector where a separate public in-house enterprise provided services to municipal organizations. The target workplaces did not entirely fulfill the Finnish legislative definition of a shared workplace since the municipality acts as an employer for both the employees of the public in-house enterprise providing the meal and cleaning services as well as the schools and kindergartens. However, the situation is similar to that of many actual shared workplaces: The employees come from various organizational backgrounds to carry out their own tasks in a work environment where employees of other organizations simultaneously carry out their own work in such a manner that their actions could have an effect on the health and safety of other employees. Due to the outsourcing of operations to other businesses or separate business units, these kinds of situations are common in today's work life. This type of organizational complexity sets new challenges for many branches of industry, including the municipal sector, even beyond those branches where shared workplaces have traditionally been widespread, such as the construction or manufacturing industries. 
At the aforementioned workplaces, the cooperation and collaboration of the different stakeholders or actors are needed to manage the worksite OSH challenges. In this study, this was aimed for by bringing the representatives of various stakeholder groups around the same table at participatory development workshops. Identifying and engaging all relevant stakeholder groups to the OSH development process was the first research task.

Identifying microergonomic development needs and finding solutions to them in participatory manner was the second research task. The implementation of the solutions that were suggested in the workshops for the different development challenges called for actions from various stakeholders. In the case of most of the proposed solutions, it was the action of an actor other than a representative of the meal and cleaning services provider that was needed in order to enact the solution proposal. The actors who are needed to implement the possible solutions for each development challenge are presented in Table 3 regarding the work system elements of organization, task, and tools and technology, and in Table 4 regarding the work system element of work environment. In addition, it is noteworthy that the actions of several stakeholders might be needed in order to spread good practices to other worksites of the municipal organization. Acknowledging the role of communication between the employee groups and enhancing it could increase the quality and functionality of the work environment. This could also lead to the teachers and other employees of the school being able to concentrate more on their core tasks [30].

The limitations of this study are discussed in the following paragraphs. First, the number of target workplaces was six, which is quite low. On the other hand the sample contained kindergartens and schools with various characteristics and the target 
workplaces were carefully selected by a multi-professional working group in order to form a representative sample, as mentioned in the Methods section. The focus of the study was on meal and cleaning services provided by a public in-house enterprise, and other support services present at the target workplaces were not looked into.

The role of the researchers in gathering the empirical data was pronounced through the chosen methods that contained direct observation of work and participatory development sessions, where the researchers acted as facilitators. The researchers observed the work of the employees as it was carried out in everyday situations. Despite the possible slight changes in the behavior of the observed employees during the observation due to being observed, the fact that the resulting development challenges were jointly discussed in the participatory development sessions with several actors speaks for the soundness of these challenges. In the sessions the ideas and possible solutions were brought up by the employees themselves. The researchers' role as facilitators of the session was to form an accepting atmosphere where the views of all participants would be heard. The activity of the individuals participating in the sessions varied, but in general all the participants were able to bring out their ideas. Also the presence of OSH representative of the employees had a positive effect on the sessions due to her knowledge on how to approach different challenges and possible solutions.

Altogether, this study presents a development process entailing both microand macroergonomic levels that takes advantage of the concept of a shared workplace in the municipal sector. Despite the above mentioned limitations, we see that these results can be generalized to similar situations in municipal kindergartens and schools where there is a public in-house enterprise providing meal and cleaning services. Similar situations are also possible regarding other support services as well. The model 
for the management of harmful load factors at shared workplaces, which was formulated as the third research task, is generalizable to various organizational situations in the municipal sector.

Table 3. The actors needed to implement the possible solutions for each development challenge regarding the work system elements of organization, task, and tools and technology.

\section{INSERT TABLE 3 HERE}

Table 4. The actors needed to implement the possible solutions for each development challenge regarding the work system element of work environment.

INSERT TABLE 4 HERE

\subsection{Conclusions}

This study aimed to identify the physical and psychosocial load factors in the work of the meal and cleaning services employees working within shared worksites at kindergartens and schools as well as to find practical solutions to observed challenges in their work. The identified load factors were divided into 15 development challenge themes, and solutions were found to almost all of these challenges in workshops that engaged all relevant stakeholder groups of these shared workplaces. Also the actors needed to implement the solutions for each development challenge were identified.

This study provides an example of how OSH management in the complex organizational environment of the public sector could benefit from the concept of a shared workplace, along with engaging all relevant stakeholder groups in OSH 
development. Furthermore, the development process presented in this study can be applied to various situations where there are several stakeholder groups or actors working at the same workplace. A management model for the work ability at municipal workplaces based on the development process carried out in this study was also suggested.

The theme of this study is timely in today's changing work life, where shared workplaces and similar situations, where there are employees from several organizations or individual business units working at the same workplace, are becoming more and more widespread. This development concerns a wide range of industries. Simultaneously, due to demographic changes and increasing pressures to lengthen work careers, the work ability of the employees - and the management of it - becomes more important.

Subjects for future research include spanning the review of shared workplaces and similar situations into a wide variety of support services needed in the municipal sector. Also examining branches of industries other than those traditionally connected with shared workplaces, such as construction or manufacturing industry, could prove to be fruitful subject for study. In addition to municipal sector studied in this research, these could include e.g. healthcare and field of trade.

\subsection{Acknowledgements}

This study was carried out as part of the "Work Ability Management at a Shared Workplace" project. The study was funded by the Public Sector Pensions Institution in Finland. 


\section{References}

[1] Reiman A, Ahonen G, Juvonen-Posti P, Heusala T, Takala EP, Joensuu M. Economic impacts of workplace disability management in a public enterprise. International Journal of Public Sector Performance Management. 2017; 3(3): 297-310.

[2] Reiman A, Väyrynen S. Holistic well-being and sustainable organisations - A review and argumentative propositions. International Journal of Sustainable Engineering. 2018; 11(5), 321329.

[3] Schulte P, Vainio H. Well-Being at work - Overview and perspective. Scandinavian Journal of Work Environment and Health. 2010; 36(5): 422-429.

[4] Bliese PD, Edwards JR, Sonnentag S. Stress and well-being at work: A century of empirical trends reflecting theoretical and societal influences. Journal of Applied Psychology. 2017; 102(3): 389-402.

[5] Zink K J, Fischer K. Do we need sustainability as a new approach in human factors and ergonomics? Ergonomics. 2013; 56(3): 348-356.

[6] Nenonen S, Vasara J. Safety management in multiemployer worksites in the manufacturing industry: Opinions and co-operation and problems encountered. International Journal of Occupational Safety and Ergonomics. 2013; 19(2): 168-183.

[7] Milch V, Laumann, K. Interorganizational complexity and organizational accident risk: A literature review. Safety Science. 2016; 82: 9-17.

[8] Schulz V, Brenner W. (2010). Characteristics of shared service centers. Transforming Government: People, Process and Policy. 2010; 4(3): 210-219.

[9] Väyrynen S, Koivupalo M, Latva-Ranta J. A 15-year development path of actions towards an integrated management system: description, evaluation and safety effects within the process industry network in Finland. International Journal of Strategic Engineering Asset Management. 2012; 1(1): 3-32. 
[10] Koivupalo M, Junno H, Väyrynen S. Integrated management within a Finnish industrial network: Steel mill case of HSEQ assessment procedure. In: Väyrynen S, Häkkinen K, Niskanen T, editors. Integrated occupational safety and health management. Solutions and industrial cases. Cham, Switzerland: Springer International Publishing; 2015. p. 41-67.

[11] Kekkonen P, Pohjosenperä T, Kantola H, Väyrynen S. Rational and participative task allocation between the nursing staff and the logistics support service provider in healthcare. Human Factors and Ergonomics in Manufacturing and Service Industries. 2018; 1-13.

[12] Nenonen S. Fatal workplace accidents in outsourced operations in the manufacturing industry. Safety Science. 2001; 49: 1394-1403.

[13] Nenonen S. Implementation of Safety Management in Outsourced Services in the Manufacturing Industry. Tampere University of Technology, Tampere. Publication: 1023, 2012. [14] Occupational Safety and Health Act. 738/2002. Chapter 6: Special situations of organising work. Finland: Ministry of Social Affairs and Health; 2002. Unofficial translation. Available from: http://www.finlex.fi /en/laki/kaannokset/2002/en20020738.pdf.

[15] Väyrynen S, Häkkinen K, Niskanen T. (eds.). Integrated Occupational Safety and Health Management. Solutions and Industrial Cases. Springer International Publishing; 2015.

[16] Lind S, Nenonen, S. Occupational risks in industrial maintenance. Journal of Quality in Maintenance Engineering. 2008; 14(2): 194-204.

[17] Valluru, CT, Dekker S, Rae A. How and why do subcontractors experience different safety on high-risk work sites? Cognition, Technology \& Work. 2017; 19(4): 785-794.

[18] Fischer K, Zink KJ. Defining elements of sustainable work systems - a system-oriented approach. Work. 2012; 41: 3900-3905.

[19] Väyrynen S, Jounila H, Latva-Ranta J, Pikkarainen S, von Weissenberg, K. HSEQ assessment procedure for supplying network: A tool for promoting sustainability and safety culture in SMEs. In: Arezes P, Rodrigues de Carvalho, PV, editors. Ergonomics and human 
factors in safety management. Industrial and Systems Engineering Series, CRC Press. Boca Raton, FL: Taylor \& Francis Group; 2016. p. 83-108.

[20] Carayon P. The balance theory and the work system model ... twenty years later. International. Journal of Human-Computer Interaction. 2009; 25(5): 313-327.

[21] Hendrick HW, Kleiner BM. Macroergonomics - An Introduction to Work System Design. Santa Monica, CA: Human Factors and Ergonomics Society; 2001.

[22] Smith MJ, Sainfort PC. A balance theory of job design for stress reduction. International Journal of Industrial Ergonomics. 1989; 4: 67-79.

[23] Carayon P, Smith MJ. Work organization and ergonomics. Applied Ergonomics. 2000; 31: 649-662.

[24] Väyrynen S, Kiema-Junes H. Exploring blue- and white-collar employees' well-being at work system: Differences in indicators of physical and psychosocial conditions of occupational groups. International Journal of Sociotechnology and Knowledge Development. 2018; 10(2): 1434.

[25] van Eerd D, Cole D, Irvin E, Mahood Q, Keown K, Theberge N, et al. Process and implementation of participatory ergonomic interventions: A systematic review. Ergonomics. 2010; 53(10): 1153-1166.

[26] Langford J, McDonagh D (eds.). Focus groups: Supporting effective product development. London, UK: Taylor \& Francis; 2003.

[27] Spinuzzi C. The methodology of participatory design. Technical Communication. 2005; 52(2): 163-174.

[28] King PM. Participatory ergonomics: A group dynamics perspective. Work. 1994; 4(3): 195 200.

[29] Ohno T. Toyota production system: beyond large-scale production. Portland, Oregon: Productivity Press; 1988. 
[30] Ahlgren C, Gillander Gådin K. Struggle for time to teach: Teachers' experiences of their work situation. Work. 2011; 40(1): 111-118. 
Table 1. Actors in the target workplaces (crosses) and the number of representatives of each stakeholder group taking part in the participatory development sessions (in parenthesis). Many of the meal and cleaning service employees are multi-service employees who work at both meal and cleaning services. This is reflected in the $1 / 2$ numbers used in the table.

\begin{tabular}{|c|c|c|c|c|c|c|}
\hline Actors & $\mathrm{K} 1$ & $\mathrm{~K} 2$ & S1 & S2 & S3 & $\mathrm{S} 4$ \\
\hline Meal service employees & $X(1 / 2)$ & $\mathrm{X}(1)$ & $\mathrm{X}$ & $X(1 / 2)$ & $\mathrm{X}(1)$ & $\mathrm{X}(1)$ \\
\hline Cleaning service employees & $X(1 / 2)$ & $X(1)$ & $X(1)$ & $X(1 / 2)$ & $X(1)$ & $X(1)$ \\
\hline Kindergarten managers & $X(1)$ & $\mathrm{X}(1)$ & & $X(1)$ & & \\
\hline Kindergarten teachers & $\mathrm{X}(1)$ & $\mathrm{X}$ & & $\mathrm{X}$ & & \\
\hline $\begin{array}{l}\text { Early childhood special } \\
\text { education teachers }\end{array}$ & $\mathrm{X}$ & $\mathrm{X}$ & & $\mathrm{X}$ & & \\
\hline Nurses & $\mathrm{X}$ & $\mathrm{X}$ & & $\mathrm{X}$ & & \\
\hline $\begin{array}{l}\text { Kindergarten teaching } \\
\text { assistants }\end{array}$ & $\mathrm{X}$ & $\mathrm{X}$ & & $\mathrm{X}$ & & \\
\hline Headmasters & & & $X(1)$ & $\mathrm{X}$ & $\mathrm{X}(1)$ & $X(2)$ \\
\hline Teachers & & & $\mathrm{X}$ & $\mathrm{X}(1)$ & $\mathrm{X}$ & $\mathrm{X}$ \\
\hline School secretaries & & & $\mathrm{X}$ & $\mathrm{X}$ & $X$ & $X$ \\
\hline Special education teachers & & & $\mathrm{X}$ & $\mathrm{X}$ & $X$ & $\mathrm{X}$ \\
\hline $\begin{array}{l}\text { Special education teaching } \\
\text { assistants }\end{array}$ & & & $\mathrm{X}$ & $\mathrm{X}$ & $\mathrm{X}$ & $\mathrm{X}$ \\
\hline Librarians & & & & $\mathrm{X}(1)$ & & $\mathrm{X}$ \\
\hline Youth workers & & & & $\mathrm{X}(1)$ & & \\
\hline Porters & & & $X$ & $X(1)$ & $X$ & $X(1)$ \\
\hline $\begin{array}{l}\text { Service area manager of meal } \\
\text { and cleaning service provider }\end{array}$ & (1) & (1) & (1) & & (1) & (1) \\
\hline
\end{tabular}


Cleaning manager of meal

and cleaning service provider

(1)

(1)

(1)

Meal service manager of meal

and cleaning service provider

$\mathrm{OSH}$ representative of meal

and cleaning service provider

(1) (1)

(1)

(1)

(1)

HR coordinator of the meal

and cleaning service provider

Work community manager of the municipality

(1) (1) (1) (1) (1)

Total number of participants

in the workshop

$\begin{array}{llllll}5 & 7 & 5 & 9 & 7 & 9\end{array}$




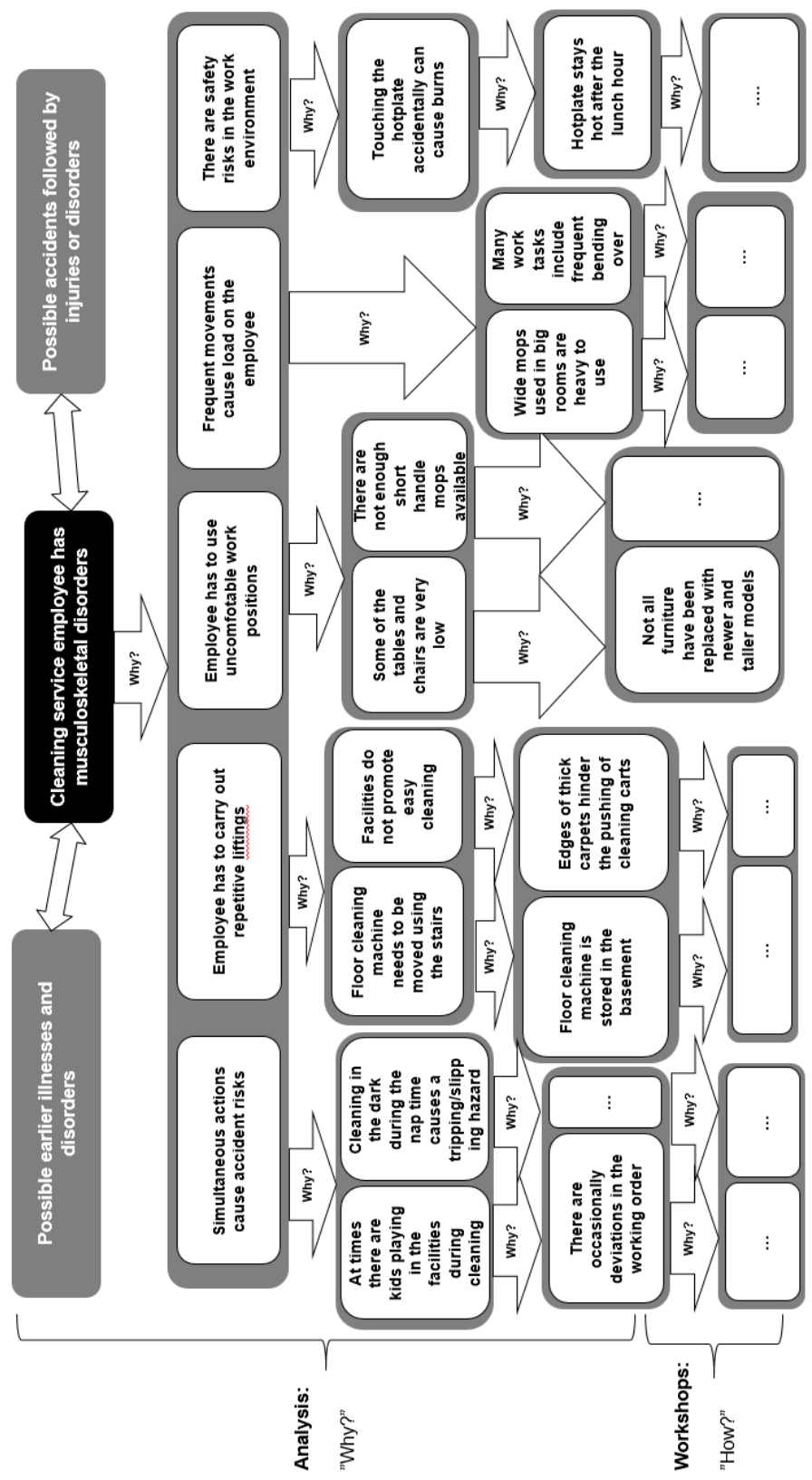

Figure 1. The results of the root cause analysis conducted on the musculoskeletal disorders caused by the physical load factors in the work of the cleaning service employees working at a kindergarten. 


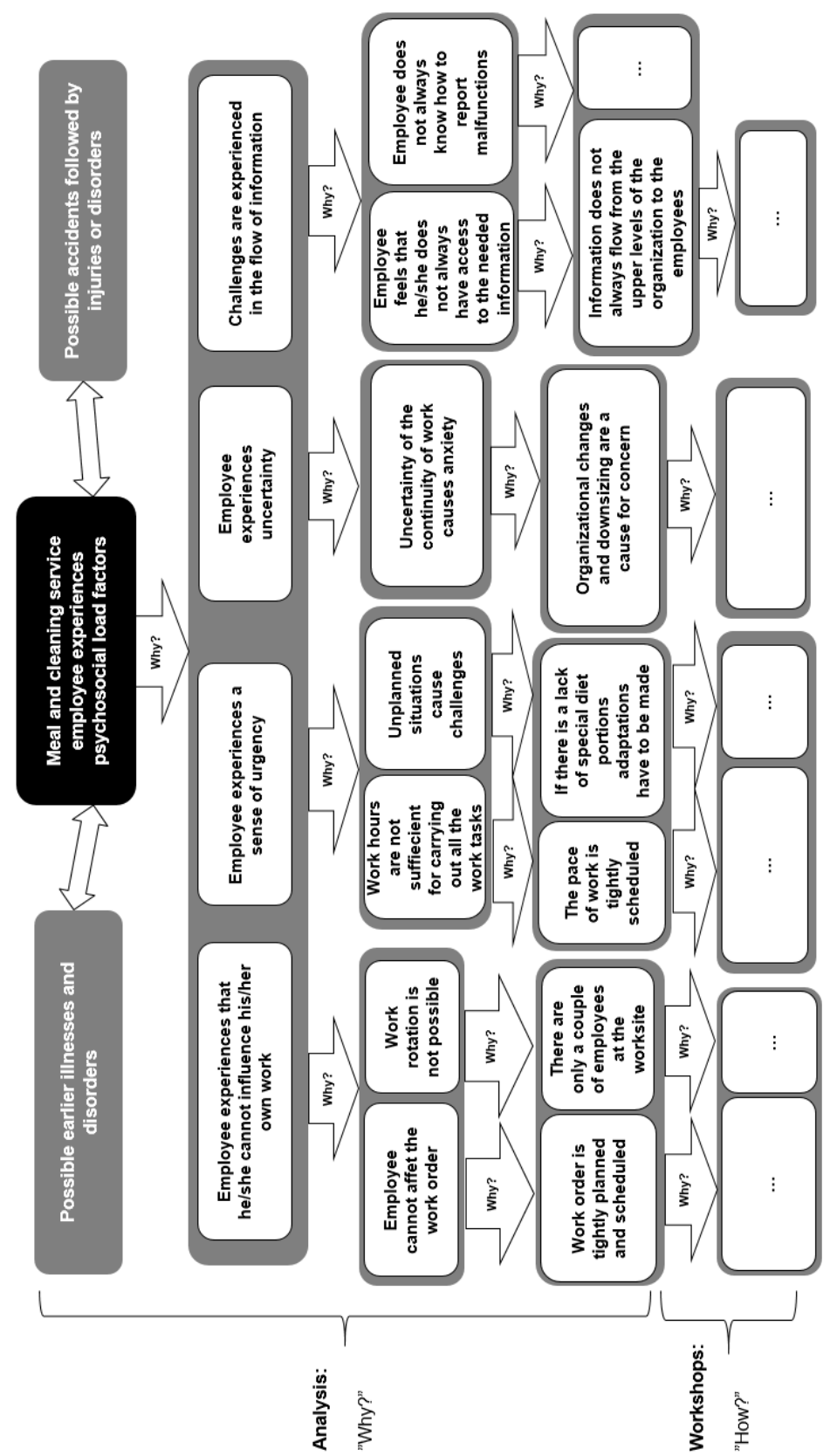

Figure 2. The results of the root cause analysis conducted on the psychosocial load factors in the work of the meal and cleaning services employees working at a kindergarten. 
Table 2. The number of development challenges identified at each kindergarten $(\mathrm{K} 1, \mathrm{~K} 2)$ and school (S1-S4) acting as a target worksite. The final column presents the number of new solutions and identified good practices suggested in the workshops.

\begin{tabular}{lccccccc}
\hline Development challenge & K1 & K2 & S1 & S2 & S3 & S4 & Solutions (N) \\
\hline Organization & $\mathbf{2}$ & $\mathbf{1}$ & $\mathbf{4}$ & $\mathbf{3}$ & $\mathbf{4}$ & $\mathbf{1}$ & $\mathbf{1 6}$ \\
Adequacy of time & 1 & 1 & 3 & 3 & 3 & 1 & 5 \\
Cooperation and flow of & 1 & - & 1 & - & 1 & - & 11 \\
information & $\mathbf{4}$ & $\mathbf{2}$ & $\mathbf{3}$ & $\mathbf{3}$ & $\mathbf{8}$ & $\mathbf{3}$ & $\mathbf{1 1}$ \\
\hline Task & 1 & 1 & 2 & 1 & 4 & 2 & - \\
Interruptions and changes & 3 & 1 & 1 & 2 & 4 & 1 & 11 \\
Lifting & $\mathbf{5}$ & $\mathbf{2}$ & $\mathbf{8}$ & $\mathbf{9}$ & $\mathbf{9}$ & $\mathbf{7}$ & $\mathbf{1 9}$ \\
\hline Tools and technology & - & - & 1 & 1 & 1 & 1 & 3 \\
Hearing protection & 3 & 1 & 2 & 5 & 5 & 2 & 8 \\
Tools and machinery & - & - & 2 & 1 & 1 & 2 & 1 \\
Work clothing & 2 & 1 & 3 & 2 & 2 & 2 & 7 \\
Work postures & $\mathbf{7}$ & $\mathbf{1}$ & $\boldsymbol{8}$ & $\mathbf{1 9}$ & $\mathbf{2 2}$ & $\mathbf{1 4}$ & $\mathbf{4 0}$ \\
\hline Work environment & 3 & 1 & 1 & 6 & 8 & 3 & 14 \\
Accident risks & 3 & - & 1 & 2 & 4 & 2 & 8 \\
Furnishings & - & - & 2 & 2 & 6 & 1 & 5 \\
Premises and materials & 1 & - & 1 & 4 & - & 2 & 6 \\
Simultaneous actions & - & - & - & 2 & 2 & 3 & 2 \\
Tidiness of premises & - & - & 2 & 1 & 1 & 1 & 1 \\
Ventilation & - & - & 1 & 2 & 1 & 2 & 4 \\
Waste management & & & & & & &
\end{tabular}




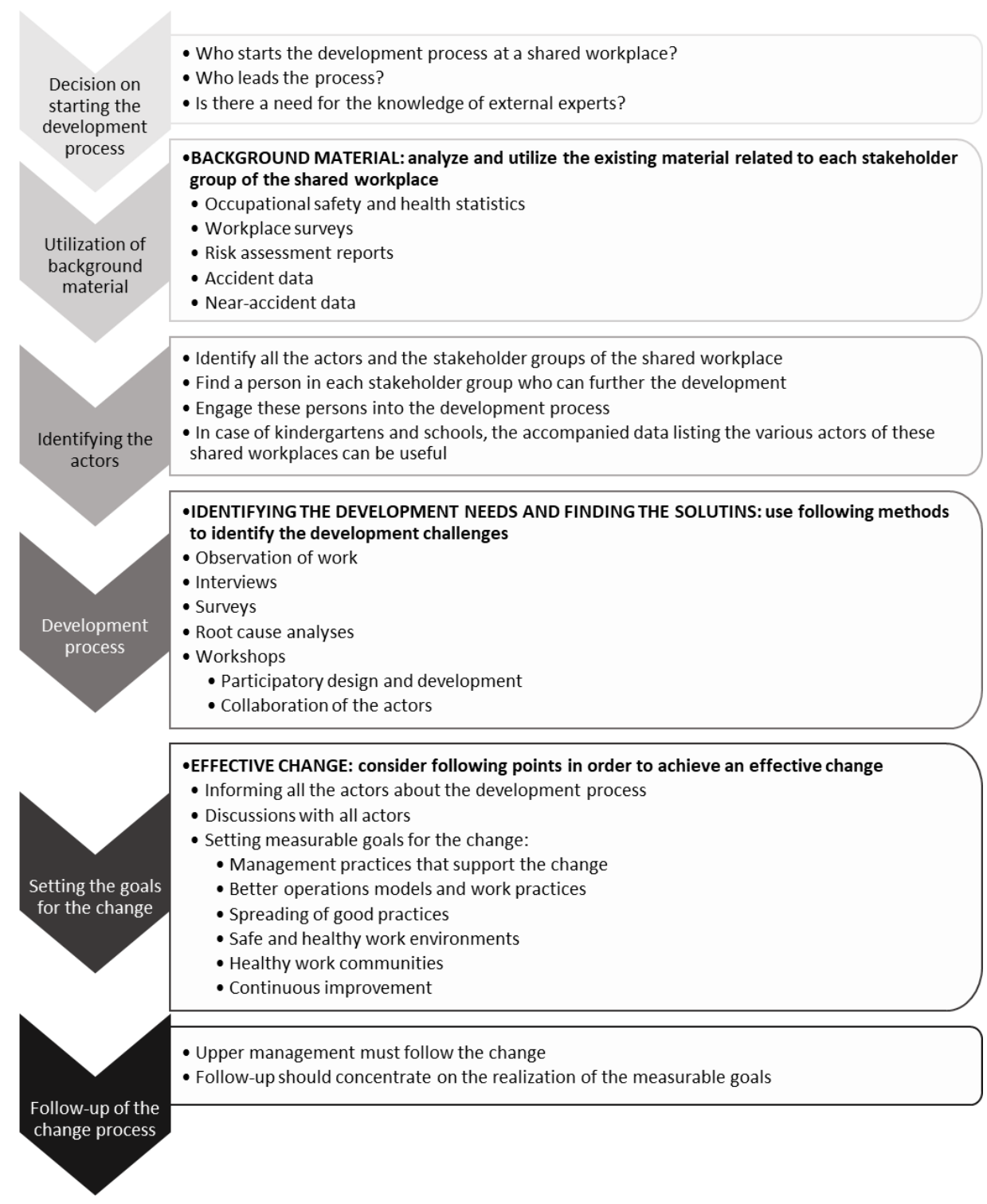

Figure. 3. The model formed for the management of physical and psychosocial load factors at shared workplaces in the municipal sector. 
Table 3. The actors needed to implement the possible solutions for each development challenge regarding the work system elements of organization, task, and tools and technology.

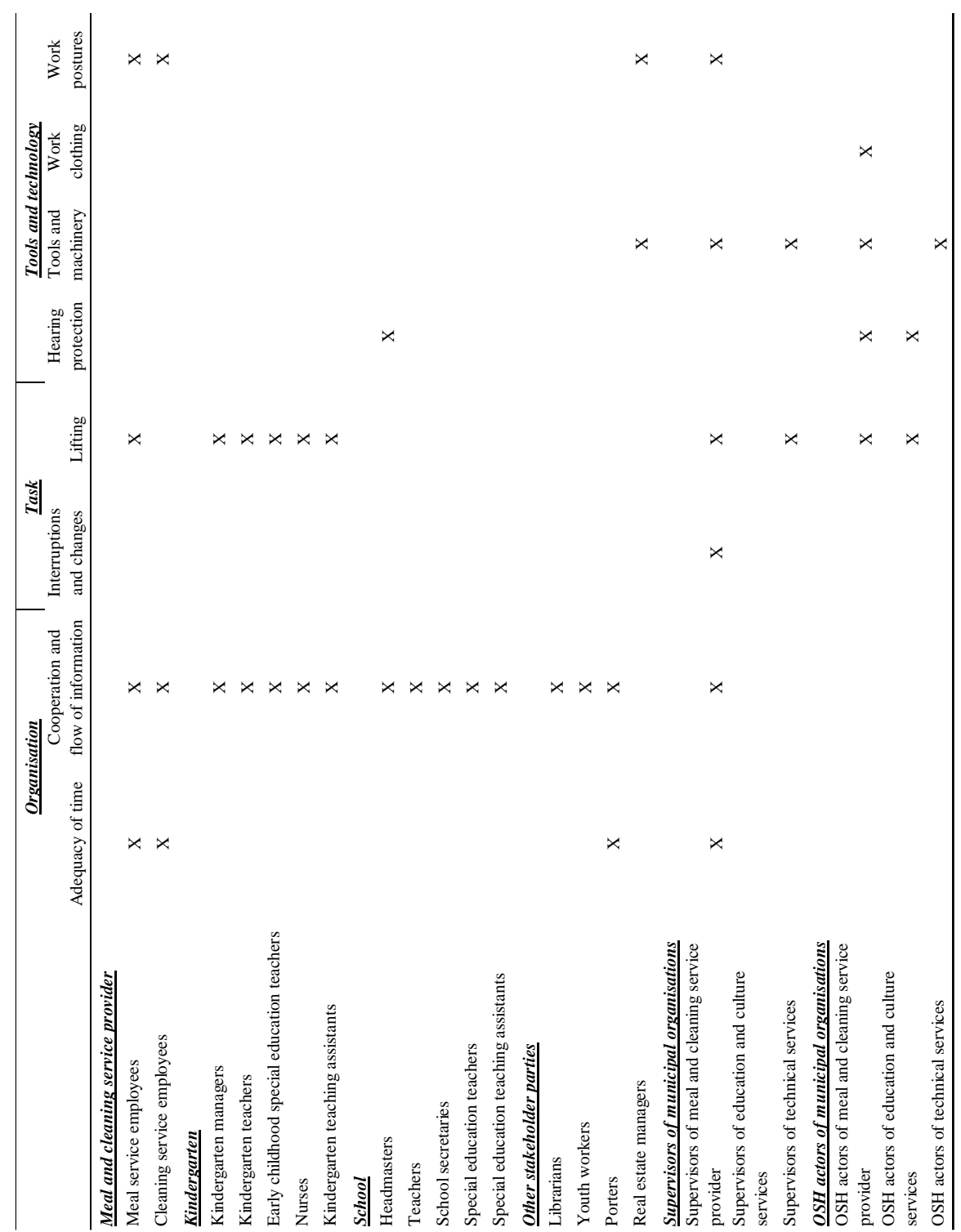


Table 4. The actors needed to implement the possible solutions for each development challenge regarding the work system element of work environment.

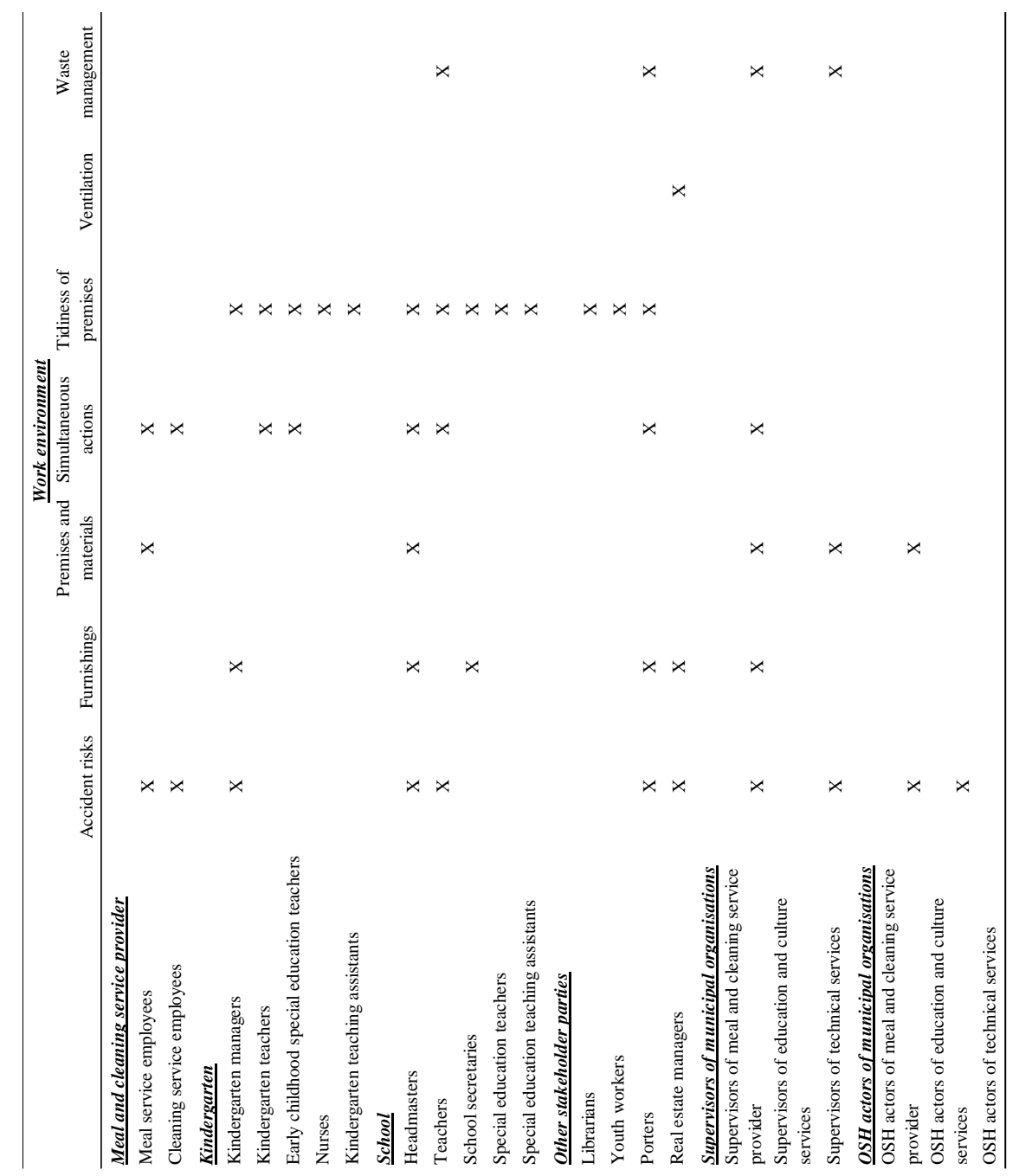

